\title{
From 3D mapping to 3D modelling: a case study from the Skaergaard intrusion, southern East Greenland
}

\author{
Kristian Svennevig and Pierpaolo Guarnieri
}

The powerful 3D mapping tool at the photogrammetry laboratory of the Geological Survey of Denmark and Greenland (GEUS) is ideal for collecting high-quality 3D geological data in remote and inaccessible areas with a high degree of exposure such as Greenland (Vosgerau et al. 2010). So far this $3 \mathrm{D}$ mapping tool has been used to visualise and extract very precise geological data from aerial and oblique photographs. In the study reported on here, the 3D mapping tool was used to generate data for $3 \mathrm{D}$ geological modelling. The Skaergaard intrusion (Fig. 1) is a well-known Eocene layered gabbro. The study of the intrusion has had great importance for the understanding of magmatic petrology, magma differentiation and fractional crystallisation since the early studies by Wager $\&$ Deer (1939). It was chosen for 3D modelling because it is well studied from a petrological point of view and because the shape of the magma chamber was previously modelled in a network of 2D cross sections (Nielsen 2004). In this paper, it is modelled for the first time in $3 \mathrm{D}$ using a detailed 1:20 000 scale geological map (McBirney 1989), 1:27 000 scale aerial photographs from 1973, data from drill holes and geophysical data.

\section{D mapping}

The 1:27 000 scale aerial photographs where scanned, triangulated and georeferenced with Socketset software. The geological map was digitised as well as georeferenced using 1:150 000 scale aerial photographs and finally draped on a high-resolution $(10 \times 10 \mathrm{~m}$ grid $)$ digital elevation model derived from the 1:27 000 scale aerial photographs. Geological features were drawn as polylines from both the aerial photographs and the geological map. Visible parts of the outer boundary were collected using the 3D stereoplotter (Fig. 2A) with very high accuracy (Vosgerau et al. 2010). Oblique aerial photos were not used for 3D-mapping as the area is not sufficiently covered and the setting up of the few available photo lines is beyond the scope of this paper. Other boundaries defined from mineral parageneses and compositions (Wager \& Brown 1968) were digitised from the 1:20 000 map in ArcGIS. The boundaries from the aerial photographs are much more accurate than those of the map (Fig. 3) because they represent directly observable geological features.
Furthermore polylines from the aerial photographs have real 3D coordinates measured directly on the 3D stereo plotter, whereas polylines from the ArcGIS map have X-Y coordinates from the map and $\mathrm{Z}$ coordinates imported from the digital elevation model. This leads to additional uncertainty as elevations in the ArcGIS map and the digital elevation model are not generated from the same source and sometimes do not overlap in the entire area of interest.

Structural readings (dip direction and dip angle) for the geological boundaries were generated from polylines using the in-house-developed software tool GEUS Planes (Fig. 2B). This tool calculates strike, dip and standard deviations on strike and dip for each node (vertex) of a polyline, generating large amounts of strike-dip measurements from the $3 \mathrm{D}$ geometry of the geological boundaries.

\section{D modelling and discussion}

The 3D modelling of the Skaergaard intrusion was carried out using the software tool Leapfrog-3D. This software can generate surfaces and volumes from structural readings,

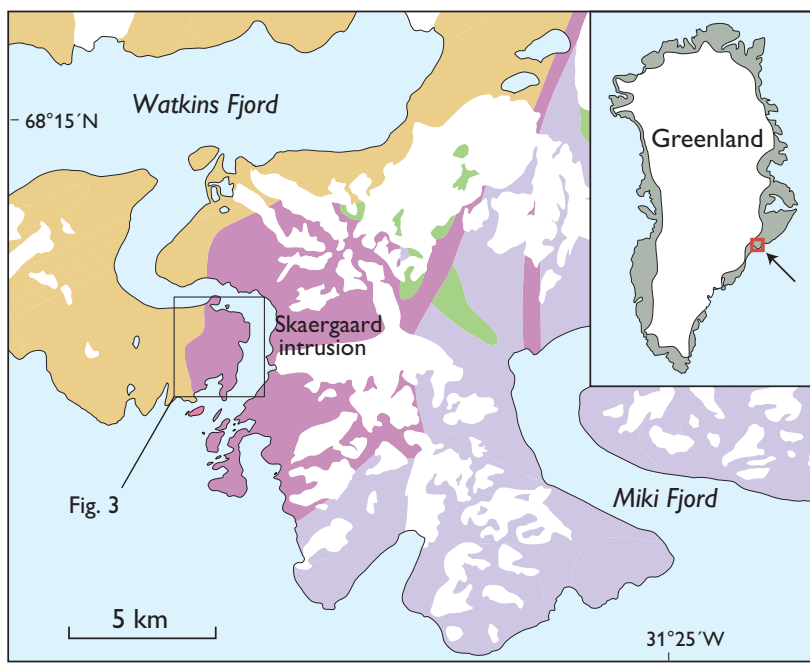

$\square$ Mainly Palaeogene volcanic rocks

Palaeogene gabbro, including the Skaergaard intrusion

Mesozoic

Precambrian basement

Glaciers

Fig. 1. The Skaergaard intrusion area, southern East Greenland. 


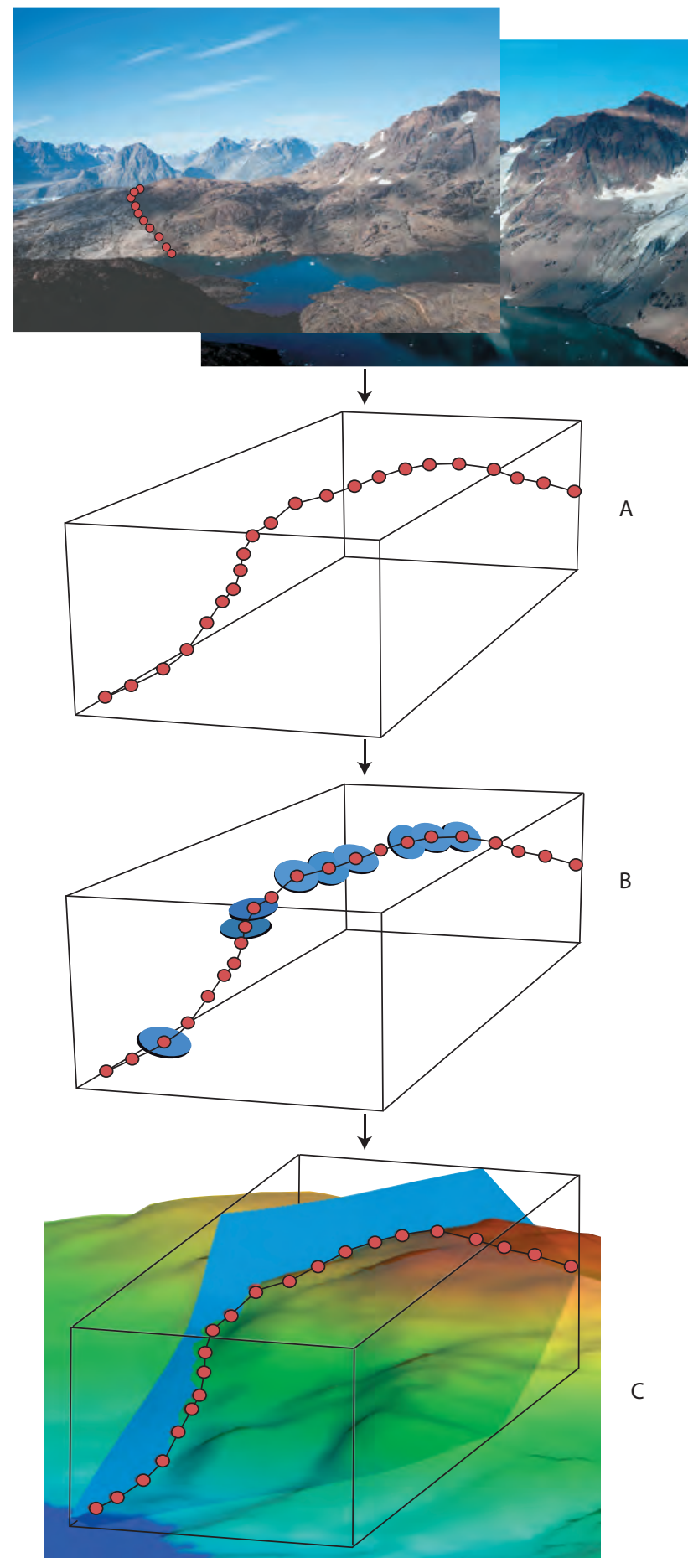

Fig. 2. Simplified workflow diagram describing the process of generating 3D data from photographs to 3D modelling. A: polylines representing geological boundaries or structures are extracted from a 3D stereo plotter. B: The nodes of the polylines are converted into structural readings (here shown as small blue discs) using the GEUS Planes tool. Measurements with a poorly defined plane (high standard deviation on either the dip, dip-azimuth or plane) are discarded. C: The structural readings are imported into a 3D modelling software (Leapfrog 3D) where surfaces and volumes can be generated and compiled to a 3D model of the geological object.
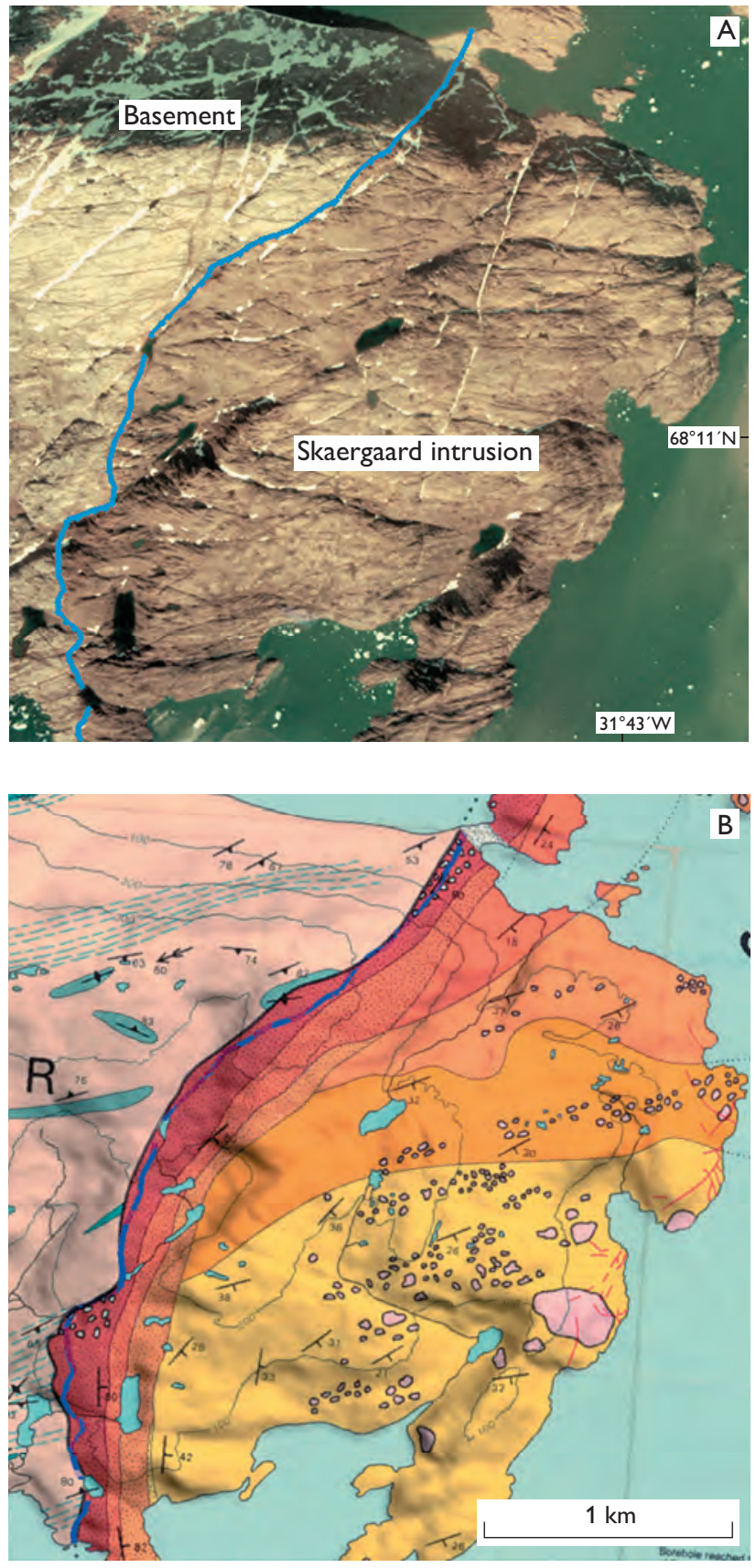

Fig. 3. Example of a polyline (blue) representing the boundary between the Skaergaard intrusion (dark grey in Fig. 3A, light yellow to red in Fig. $3 \mathrm{~B}$, representing different lithological units) and the basement (light grey in Fig. 3A, light skin tone in Fig. 3B). The same polyline is drawn on the 1:27 000 aerial photographs (A) and shown on the geological map of McBirney (1989) (B) for comparison. The difference between the locations of the two lines is up to $100 \mathrm{~m}$. 
points and polylines (Fig. 2C). In standard surface modelling, only a couple of structural readings are used for generating surfaces. The great number of structural readings produced by GEUS Planes present a problem to the modelling software making it necessary to manually select which strike-dip measurements to use for the construction of surfaces. This complication will be solved in a forthcoming upgrade of the GEUS Planes tool by changing the output and by using modelling software that can import the standard deviation as a parameter and use it to estimate the quality of the structural readings in the creation of surfaces.

In areas with no pre-Quaternary exposures, such as glaciated areas or water-covered areas, support points were introduced to guide the surfaces. Drill-hole data were also imported along with a geophysical gravity model of the floor of the intrusion (T.M. Rasmussen, personal communication 2011) to further improve the model. Due to erosion and lack of exposures the locations of the roof and northern boundary
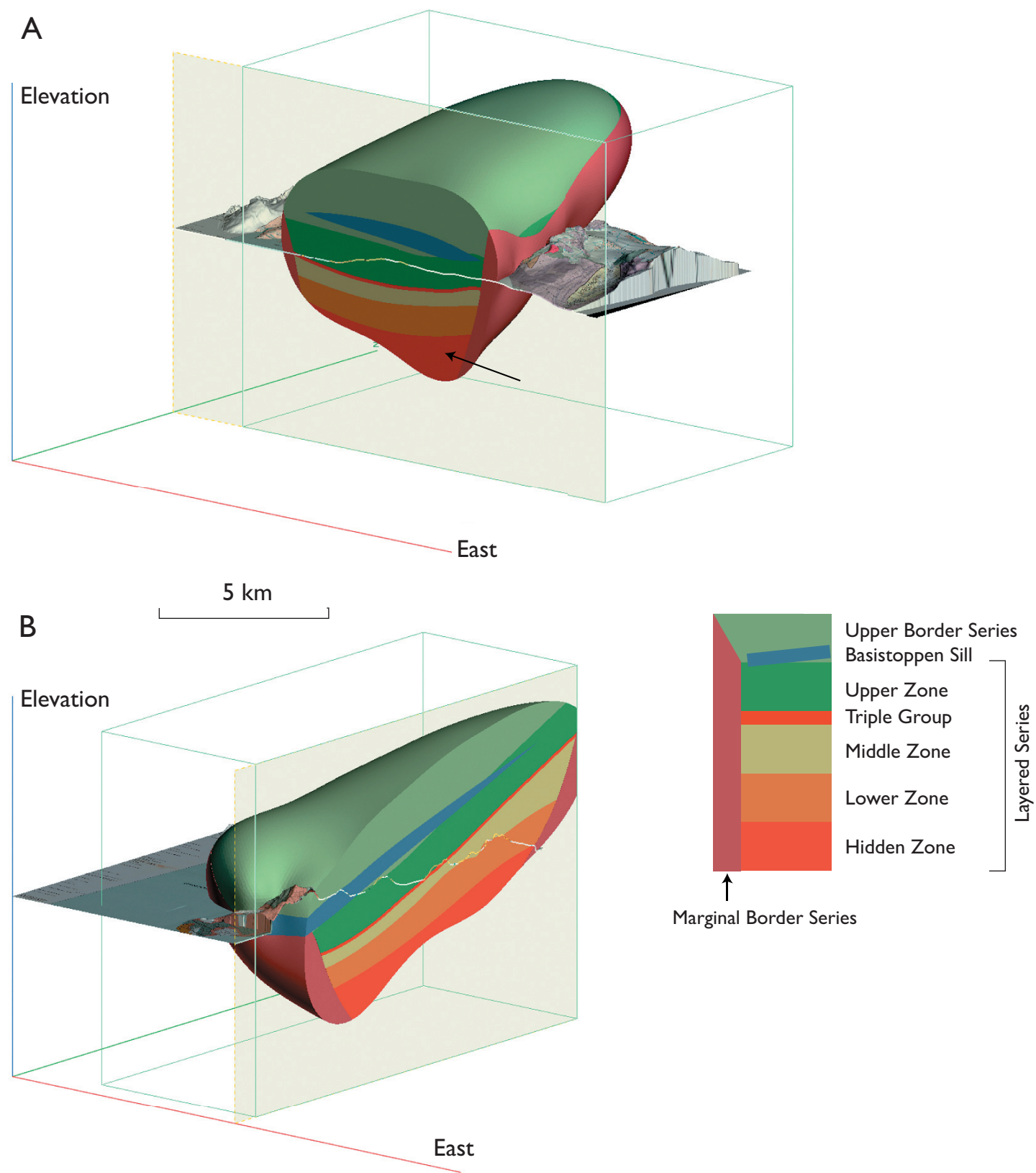

Fig. 4. 3D model of the Skaergaard intrusion in E-W (A) and N-S (B) sections. The view is towards $320^{\circ}$ at a plunge of $15^{\circ}$. No vertical exaggeration. Notice the wedge-like shape of the Hidden Zone (black arrow in A). 
of the intrusion are poorly constrained, and these were modelled with considerable uncertainty. Two structural readings (strike/dip, 180/20 S and 180/10 S) were constructed to guide the roof surface of the magma chamber. These orientations were estimated by extrapolating the roof boundary in the southern part of the intrusion (Wager \& Deer 1939; Nielsen 2004) with the regional dip $\left(10-20^{\circ} \mathrm{S}\right)$ of the Tertiary strata hosting the intrusion (Nielsen \& Brooks 1981).

The geophysical model for the floor of the intrusion has the same dip as the regional strata of $10-20^{\circ} \mathrm{S}$ but also shows a dip of around $15^{\circ}$ towards the east that is unexpected from the surface and drill-hole data used for generating the model. This is reflected in the wedge-like shaped of the Hidden Zone in the 3D model (Fig. 4A). Furthermore, the modelled floor of the intrusion near the northern boundary is located much more deeply than expected. Based on a single drill hole in the northern part of the intrusion that reaches the contact zone of the floor (Holness et al. 2007), unexposed gabbro of the intrusion is estimated to reach a depth of no more than $450 \mathrm{~m}$ (T.F.D. Nielsen, personal communication 2012), whereas the geophysical model predicts $1450 \mathrm{~m}$. Several explanations can be suggested for this discrepancy: (1) The density of the gabbro at the northern margin may be underestimated, (2) uncertainty of the floor depth from drill-hole data or (3) rock types below the floor of the intrusion may have unexpected high densities. Irrespective of the various uncertainties, the preliminary estimate of the total volume of the intrusion is between 279 and $305 \mathrm{~km}^{3}$ (depending on different estimates of the northern boundary). This is in good agreement with a previous estimate of $280 \pm 23 \mathrm{~km}^{3}$ (Nielsen 2004).

The Triple Group (Fig. 4), defined by three distinctive leucocratic layers in the uppermost part of the Middle Zone, is of particular interest as it is rich in palladium and gold (Bird et al. 1991; Nielsen et al. 2005). The degree of detail in the model presented here is too low for a thorough investigation of these levels, but our data reflect the concave nature of the layers (Fig. 4) also described by Nielsen (2004). Future expansion of the model with data from oblique photographs can greatly improve our understanding of the Triple Group, because it is clearly seen on photographs (fig. 11c in Brooks 2011), being well exposed on the steep mountain slopes.

\section{Concluding remarks}

The 3D mapping tool at the GEUS photogrammetry laboratory is ideal for generating high quality data for 3D modelling. It is, however, necessary to fine-tune the GEUS Planes tool and to conduct the modelling in a more advanced software such as GoCAD or Move in order to take full advantage of the high quality and quantity of the data. With these software tools, it is also possible to do advanced modelling and, for example, carry out balanced unfolding and backstripping of geological structures and units.

\section{Acknowledgements}

Max Nykjær Strunck is thanked for setting up the aerial photographs and for helping with the digital elevation model. Thorkild Maack Rasmussen is thanked for producing the geophysical model and Troels F.D. Nielsen is thanked for valuable discussion of the geology of the Skaergaard intrusion.

\section{References}

Bird, D.K., Brooks, C.K., Gannicott, R.A. \& Turner, P.A. 1991: A goldbearing horizon in the Skaergaard intrusion, East Greenland. Economic Geology 86, 1083-1092.

Brooks, C.K. 2011: The East Greenland rifted volcanic margin. Geological Survey of Denmark and Greenland Bulletin 24, 96 pp.

Holness, M.B., Nielsen, T.F.D. \& Tegner, C. 2007: Textural maturity of cumulates: a record of chamber filling, liquidus assemblage, cooling rate and large-scale convection in mafic layered intrusions. Journal of Petrology 48, 141-157.

McBirney, A.R. 1989: Geological map of the Skaergaard intrusion, East Greenland. Eugene, USA: University of Oregon (map sheet).

Nielsen, T.F.D. 2004: The shape and volume of the Skaergaard intrusion, Greenland: implications for mass balance and bulk composition. Journal of Petrology 45, 507-530.

Nielsen, T.F.D. \& Brooks, C.K. 1981: The East Greenland rifted continental margin: an examination of the coastal flexure. Journal of the Geological Society (London) 138, 559-568.

Nielsen, T.F.D., Andersen, J.C.Ø. \& Brooks, C.K. 2005: The Platinova Reef of the Skaergaard intrusion. In: Mungal, J.E. (ed.): Exploration for platinum group element deposits. Mineralogical Association of Canada Short Course Series 35, 431-455.

Vosgerau H., Guarnieri P., Weibel R., Larsen M., Dennehy, C., Sørensen, E.V. \& Knudsen, C. 2010: Study of a Palaeogene intrabasaltic sedimentary unit in southern East Greenland: from 3-D photogeology to micropetrography. Geological Survey of Denmark and Greenland Bulletin 20, 75-78.

Wager, L.R. \& Deer, W.A. 1939 (re-issued 1962): Geological investigations in East Greenland. Part III. The petrology of the Skaergaard intrusion, Kangerdlugssuaq, East Greenland. Meddelelser om Grønland 105(4), 352 pp.

Wager, L. R. \& Brown, G.M. 1968: Layered igneous rocks, 588 pp. Edinburgh: Oliver and Boyd. 